\title{
Suppression of cap-dependent translation in mitosis
}

\author{
Stéphane Pyronnet, ${ }^{1,2}$ Josée Dostie, ${ }^{1,3}$ and Nahum Sonenberg ${ }^{4}$ \\ Department of Biochemistry and McGill Cancer Center, McGill University, Montreal, Quebec H3G 1Y6, Canada
}

Cap-dependent translation is mediated by eIF4F, a protein complex composed of three subunits as follows: eIF4E, which recognizes the mRNA 5' cap structure; eIF4A, an RNA-helicase; and eIF4G, a scaffolding protein that binds eIF4E, eIF4A, and the eIF4E-kinase Mnk1 simultaneously. eIF4E is hypophosphorylated and cap-dependent translation is reduced at mitosis. Here, we show that 4E-BP1, a suppressor of eIF4E function, is also hypophosphorylated in mitosis, resulting in disruption of the eIF4F complex. Consequently, eIF4E is sequestered from the eIF4G/Mnk1 complex. These results explain the specific inhibition of cap-dependent translation in mitosis and also explain how eIF4E is rendered hypophosphorylated during mitosis.

Furthermore, eIF4E interaction with eIF4GII is strongly decreased coincident with hyperphosphorylation of eIF4GII. Thus, inhibition of cap-dependent translation in mitosis results from a combination of phosphorylation modifications leading to eIF4F complex disruption.

[Key Words: Translation initiation; mitosis; cap-binding complex; internal ribosome entry site]

Received February 20, 2001; revised version accepted June 29, 2001.

All nuclear-encoded eukaryotic mRNAs are modified at their $5^{\prime}$ end with a structure termed cap $\left(\mathrm{m}^{7} \mathrm{GpppN}\right.$, in which $\mathrm{N}$ is any nucleotide; Shatkin 1976). The cap plays a key role in facilitating ribosome binding to the mRNA 5' end (Shatkin 1976). The function of the cap structure is mediated by eIF4F, an eukaryotic initiation factor complex composed of three subunits, eIF4E (the capbinding protein), eIF4A (an RNA helicase), and eIF4G (Gingras et al. 1999). The amino-terminal third of eIF4G interacts with eIF4E, whereas its carboxy-terminal twothirds contains binding sites for eIF4A and eIF3, an initiation factor complex associated with the 40S ribosomal subunit (Hershey and Merrick 2000). Thus, eIF4G functions to bridge the ribosome to the mRNA $5^{\prime}$ end by virtue of its simultaneous interactions with eIF3 and eIF4E. eIF4A, in conjunction with the RNA-binding factor eIF4B, is believed to facilitate ribosome binding by unwinding the mRNA $5^{\prime}$ secondary structure, which is inhibitory for ribosome binding (Pelletier and Sonenberg 1985). There are two functional homologs of eIF4G in mammals, termed eIF4GI and eIF4GII. The eIF4Gs share $46 \%$ identity, and exhibit similar biochemical activities (Gradi et al. 1998).

eIF4E is the least abundant of all initiation factors

\footnotetext{
${ }^{1}$ These authors contributed equally to this work.

Present addresses: ${ }^{2}$ INSERM U531, Institut Louis Bugnard, CHU Rangueil, 31403 Toulouse, France; ${ }^{3}$ Department of Biochemistry and Biophysics, University of Pennsylvania School of Medicine, Philadelphia, PA 19104, USA.

${ }^{4}$ Corresponding author.

E-MAIL nsonen@med.mcgill.ca; FAX (514) 398-1287.

Article and publication are at http://www.genesdev.org/cgi/doi/10.1101/ gad.889201.
}

(Duncan et al. 1987), and is a major target for translational control. eIF4E is phosphorylated on Ser 209 (Flynn and Proud 1995; Joshi et al. 1995). Phosphorylated eIF4E was reported to exhibit higher binding affinity for the cap (Minich et al. 1994), and to exist preferentially in the eIF4F complex (Tuazon et al. 1990; Bu et al. 1993). The physiological eIF4E kinase is Mnk1, a recently characterized serine/threonine kinase, which is phosphorylated and activated by Erk1, Erk2, and p38 MAP kinases both in vitro and in vivo (Fukunaga and Hunter 1997; Waskiewicz et al. 1997). Mnk1 does not bind directly to eIF4E. Instead, Mnk1 is recruited to eIF4E through its direct interaction with the carboxyl terminus of eIF4G (Pyronnet et al. 1999; Waskiewicz et al. 1999). This recruitment mode is thought to ensure that eIF4E is phosphorylated only as a part of the eIF4F complex (Pyronnet et al. 1999; Waskiewicz et al. 1999), as eIF4F rather than eIF4E alone is the functional entity that mediates the effects of the cap during translation (Haghighat and Sonenberg 1997).

Mammalian eIF4E activity is modulated by its reversible association with a family of three related polypeptides termed 4E-binding proteins (4E-BPs or PHAS; Lin et al. 1994; Pause et al. 1994). The eIF4E/4E-BPs interaction is regulated by phosphorylation (Pause et al. 1994). Hypophosphorylated 4E-BPs bind tightly to eIF4E, resulting in inhibition of cap-dependent translation (Pause et al. 1994). The 4E-BPs do not inhibit eIF4E binding to the cap, but instead block eIF4F assembly by competing with eIF4Gs for a common binding site on eIF4E (Haghighat et al. 1995; Mader et al. 1995). Thus, 4E-BPs act as molecular mimics of eIF4G (Marcotrigiano et al. 1999). 
Although cap-dependent translation initiation is thought to be the prevalent mode of ribosome binding to mRNAs in eukaryotes, a growing list of viral and cellular mRNAs exhibit an inherent ability to bypass the requirement for the cap structure and, hence, the requirement for eIF4E. Ribosomes access these mRNAs by binding directly to an internal ribosome entry site (IRES). IRESes were first identified in picornavirus mRNAs, which do not possess a $5^{\prime}$ cap structure (Jang et al. 1988; Pelletier and Sonenberg 1988). During poliovirus infection, eIF4GI is cleaved by the virus-encoded protease $2 \mathrm{~A}^{\mathrm{PRO}}$, rendering the eIF4F complex inactive for cap-dependent ribosome binding, but retaining its activity in IRES-mediated translation (Etchison et al. 1982; Ohlmann et al. 1996). IRESes were discovered thereafter in cellular mRNAs, and recently two IRESes have been shown to function in a cell cycle-dependent manner (Cornelis et al. 2000; Pyronnet et al. 2000).

The rate of protein synthesis varies throughout the cell cycle (Fan and Penman 1970; for review, see Pyronnet and Sonenberg 2001). When cells enter mitosis, capdependent, but not IRES-mediated, translation initiation is impaired (Bonneau and Sonenberg 1987). The switch from cap- to IRES-dependent translation is thought to be necessary for the translation of mRNAs whose protein products are required at mitosis (Cornelis et al. 2000; Pyronnet et al. 2000; Sachs 2000). However, little is known about the molecular mechanisms that engender such a switch. The interaction between eIF4E and the cap structure is reduced in mitotic cells, which correlates with a decrease in eIF4E phosphorylation (Bonneau and Sonenberg 1987). However, the dephosphorylation of eIF4E at mitosis is rather surprising as Mnk1, the physiological kinase of eIF4E, is a direct target of MAP kinases (MAPK), which are activated during mitosis (Tamemoto et al. 1992). Furthermore, MAPKK induction is required for the $G_{2} / M$ transition (Wright et al. 1999).

Here, we investigate the mechanism of the switch from cap-dependent to IRES-mediated translation in mitosis. We show that 4E-BP1 is hypophosphorylated, and interacts strongly with eIF4E during mitosis. Consequently, eIF4G together with its associated Mnk1 kinase fail to assemble into eIF4F, thus providing an explanation for the inhibition of cap-dependent translation, and for eIF4E hypophosphorylation in spite of Mnk1 activation. Furthermore, eIF4GII hyperphosphorylation during mitosis coincides with a decrease in its binding to eIF4E. Finally, hyperphosphorylation of the recently cloned nucleocytoplasmic transporter of eIF4E (4E-T; Dostie et al. 2000a) correlates with a dramatic loss in its interaction with eIF4E. This is consistent with the nuclear envelope breakdown, and consequent lack of nucleocytoplasmic transport during mitosis.

\section{Results}

Dephosphorylation of eIF4E during mitosis in spite of Mnk1 activation

The phosphorylation status of eIF4E in HeLa cells arrested at different phases of the cell cycle was first ana- lyzed. A cell extract was probed by Western blotting with anti-eIF4E phospho-specific antibody, or an antieIF4E antibody, which recognizes both forms of the protein. The specificity of the phospho-specific anti-eIF4E antibody was verified by isoelectric focusing (Fig. 1A). As reported previously (Bonneau and Sonenberg 1987), eIF4E is phosphorylated in interphase or $\mathrm{G}_{1} / \mathrm{S}$-arrested cells (Fig. 1B, lanes 1 and 2), but becomes hypophosphorylated during mitosis (Fig. 1B, lanes 3 and 4). eIF4E dephosphorylation during mitosis is observed in cells collected either by mitotic shake-off or following nocodazole treatment, and thus, is independent of the method used to isolate mitotic cells. Also, phosphorylation of eIF4E increases following TPA treatment of starved cells (Fig. 1B, cf. lanes 5 and 6), as shown previously (Wang et al. 1998).

Mnk1 phosphorylates eIF4E both in vitro and in vivo (Waskiewicz et al. 1997, 1999; Pyronnet et al. 1999). Therefore, Mnk1 activity was examined at different phases of the cell cycle. Because endogenous Mnk1 cannot be detected directly (Fukunaga and Hunter 1997), HeLa cells were first transfected with Flag-Mnk1, and arrested at various stages of the cell cycle. Cell extract was analyzed by Western blotting with either anti-Mnk1 (Fig. 1C, top), or anti-Flag (Fig. 1C, bottom) antibody. Mnk1 from mitotic cells migrated as a doublet with reduced mobility as compared with Mnk1 from $G_{1}, G_{1} / S$, or S cells (Fig. 1C). Decreased Mnk1 electrophoretic mobility was shown previously to be caused by hyperphosphorylation and to correlate with increased kinase activity (Fukunaga and Hunter 1997). To show that Mnk1 activity is increased during mitosis, an in vitro immune complex kinase assay was performed on wild-type or mutant Mnk1, using purified recombinant eIF4E as a substrate. In spite of eIF4E dephosphorylation (Fig. 1B), Mnk1 immunoprecipitated from mitotic cells was hyperphosphorylated and more active than that of interphase cells (Fig. 1D, cf. lanes 1 and 2). As positive and negative controls, Flag-Mnk1-T344E (a constitutively active mutant) and Flag-Mnk1-TAA (a kinase-dead Tloop mutant) were used. Whereas the constitutively active mutant, which was immunoprecipitated from either unsynchronized or mitotic cells strongly phosphorylated eIF4E in vitro (Fig. 1D, lanes 3 and 4), the T-loop mutant was inactive (Fig. 1D, lanes 5 and 6). These data indicate that Mnk1 is separated from its substrate eIF4E during mitosis, and consequently, eIF4E is dephosphorylated in spite of Mnk1 activation.

\section{Decreased eIF4F complex during mitosis}

Mnk1 does not bind directly to eIF4E, but instead interacts with eIF4G (Pyronnet et al. 1999; Waskiewicz et al. 1999). Thus, a reasonable model to account for eIF4E dephosphorylation despite Mnk1 activation is that the eIF4F complex is not assembled at mitosis, and that consequently, Mnk1 does not have access to eIF4E. As hypophosphorylated 4E-BPs compete with eIF4Gs for a common binding site on eIF4E, and thereby prevent eIF4F complex assembly (Haghighat et al. 1995; Mader et 

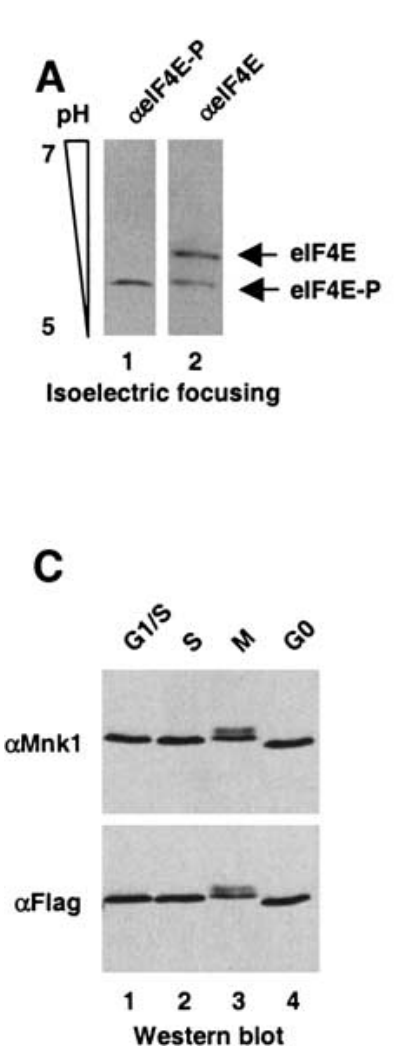

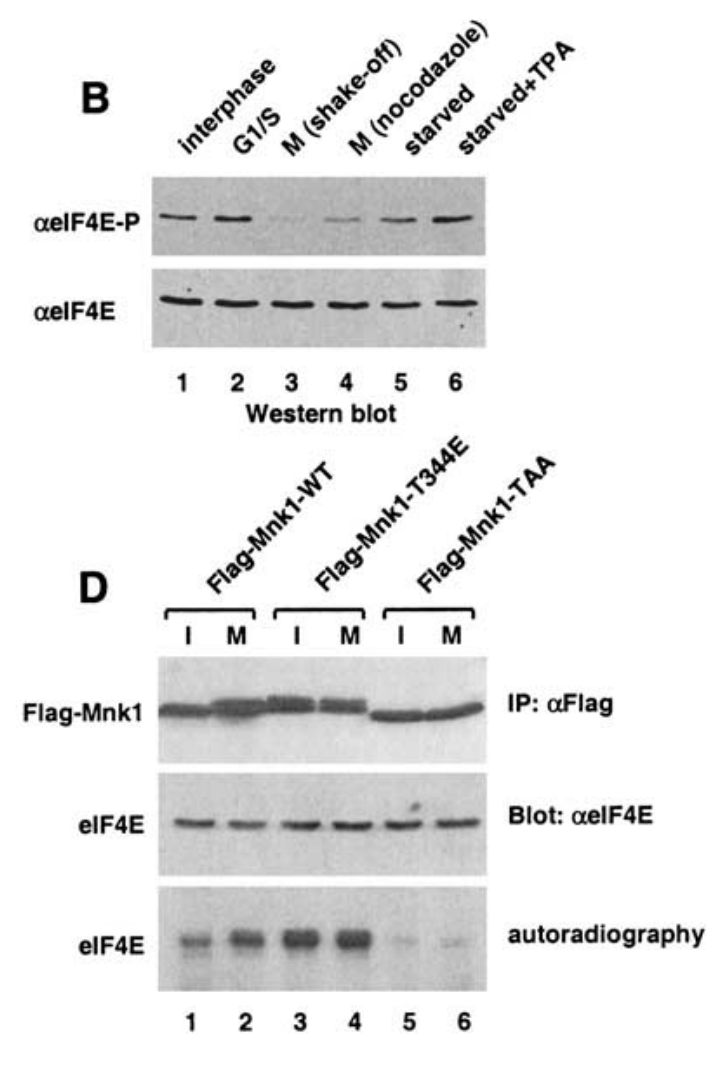

Figure 1. Decreased eIF4E phosphorylation, but increased Mnk1 activity in mitotic cells. (A) Specificity of anti-phosphospecific eIF4E antibody. Total HeLa extract from asynchronous cells was resolved by isoelectric focusing (as described in Materials and Methods), and analyzed by Western blotting with anti-phospho-specific eIF4E (lane 1), or anti-eIF4E (lane 2) antibodies. (B) eIF4E phosphorylation at different phases of the cell cycle. Total HeLa extract from interphase, aphidicolin-treated $\left(\mathrm{G}_{1} / \mathrm{S}\right)$, mitotic (M shake-off), nocodazoletreated ( $M$ nocodazole), starved, or starved and TPA-treated cells was resolved by SDSPAGE and analyzed by Western blotting with anti-phospho-specific eIF4E (top), or anti-eIF4E (bottom) antibody. (C) Mnk1 gel mobility. Total extract from cells transfected with Flag-Mnk1 and treated with aphidicolin $\left(G_{1} / S\right)$, thymidine $(S)$, nocodazole $(M)$, or extract from starved cells $\left(\mathrm{G}_{0}\right)$ was resolved by SDS-PAGE, and analyzed by Western blotting with anti-Mnk1 (top) or anti-Flag (bottom) antibody. (D) Mnk1 activation during mitosis. Extract from interphase or mitotic (nocodazole-arrested) HeLa cells transfected with FlagMnk1 wild type or mutants was immunoprecipitated with anti-Flag antibody. Immunoprecipitates were used for immune complex kinase assay using $\left[\gamma^{-32} \mathrm{P}\right] \mathrm{ATP}$ and recombinant mouse eIF4E as a substrate (as described in Materials and Methods). Samples were resolved by SDS-PAGE, and revealed by autoradiography (bottom) or by Western blotting using the indicated antibodies (top, middle).

al. 1995), we first asked whether 4E-BP1 phosphorylation is decreased during mitosis. As shown in Figure 2A, 4EBP1 is hypophosphorylated at mitosis as compared with interphase cells. The hyperphosphorylated $\varepsilon$ and $\delta$ forms are markedly reduced during mitosis, whereas the less phosphorylated $\beta$ and $\gamma$ forms increase in intensity (Fig. 2A, cf. lanes 1 and 2). Next, the interaction between eIF4E and 4E-BP1 was analyzed. Total HeLa extract from interphase or mitotic cells was analyzed by Western blotting with an anti-4E-BP1 antibody (Fig. 2B, top), or by far-Western with ${ }^{32} \mathrm{P}-\mathrm{HMK}-\mathrm{eIF} 4 \mathrm{E}$ as a probe (Fig. 2B, bottom). 4E-BP1 becomes hypophosphorylated (Fig. 2B, top, cf. lanes 1 and 2), and its affinity to eIF4E is increased during mitosis (Fig. 2B, bottom, cf. lanes 1 and 2). To determine whether the amount of eIF4F complex is altered by 4E-BP1 dephosphorylation, eIF4E from interphase or mitotic cells was incubated with a $\mathrm{m}^{7} \mathrm{GDP}$ resin, and bound proteins were analyzed by Western blotting for eIF4E, 4E-BP1, and eIF4GI. Although a slightly smaller amount of eIF4E was retained on the cap resin (Fig. 2C, top, cf. lanes 1 and 2), the interaction between eIF4E and the hypophosphorylated forms of 4EBP1 was significantly increased during mitosis (Fig. 2C, bottom, cf. lanes 1 and 2). In sharp contrast, the amount of eIF4GI in the coprecipitate was dramatically reduced (Fig. 2C, cf. lanes 3 and 4, bound). The reduced association of eIF4GI with eIF4E does not result from decreased
eIF4G levels in cells arrested at mitosis as similar amounts of eIF4GI from interphase and mitotic cells were loaded on the cap column (Fig. 2C, cf. lanes 3 and 4, input). Intriguingly, following the cap-column assay with the mitotic extract, only a slightly higher amount of eIF4GI was recovered in the flow-through (Fig. 2C, cf. lanes 3 and 4, flow-through), although there was a dramatic reduction of eIF4GI binding to the cap resin. This apparent difference is likely due to the fact that eIF4E is the least abundant of all translation initiation factors in HeLa cells (Duncan et al. 1987) and, therefore, only a fraction of eIF4GI is bound to eIF4E. Consequently, most of the eIF4GI protein is recovered in the flow-through even in interphase cells when eIF4E/eIF4GI interaction is increased. Taken together, these data indicate that eIF4F complex formation is severely compromised during mitosis.

To show that the absence of the eIF4F complex leads to a decrease in the eIF4E/Mnk1 complex, an extract from interphase or mitotic HeLa cells cotransfected with Flag-Mnk1 and HA-eIF4E was used in a coimmunoprecipitation assay. Whereas a similar amount of FlagMnk1 was immunoprecipitated from interphase and mitotic cell extracts (Fig. 2D, top, cf. lanes 1 and 2), the amount of HA-eIF4E coimmunoprecipitated with FlagMnk1 was reduced in mitotic cells (Fig. 2D, bottom, cf. lanes 1 and 2). Similar results were obtained in the re- 
Pyronnet et al.
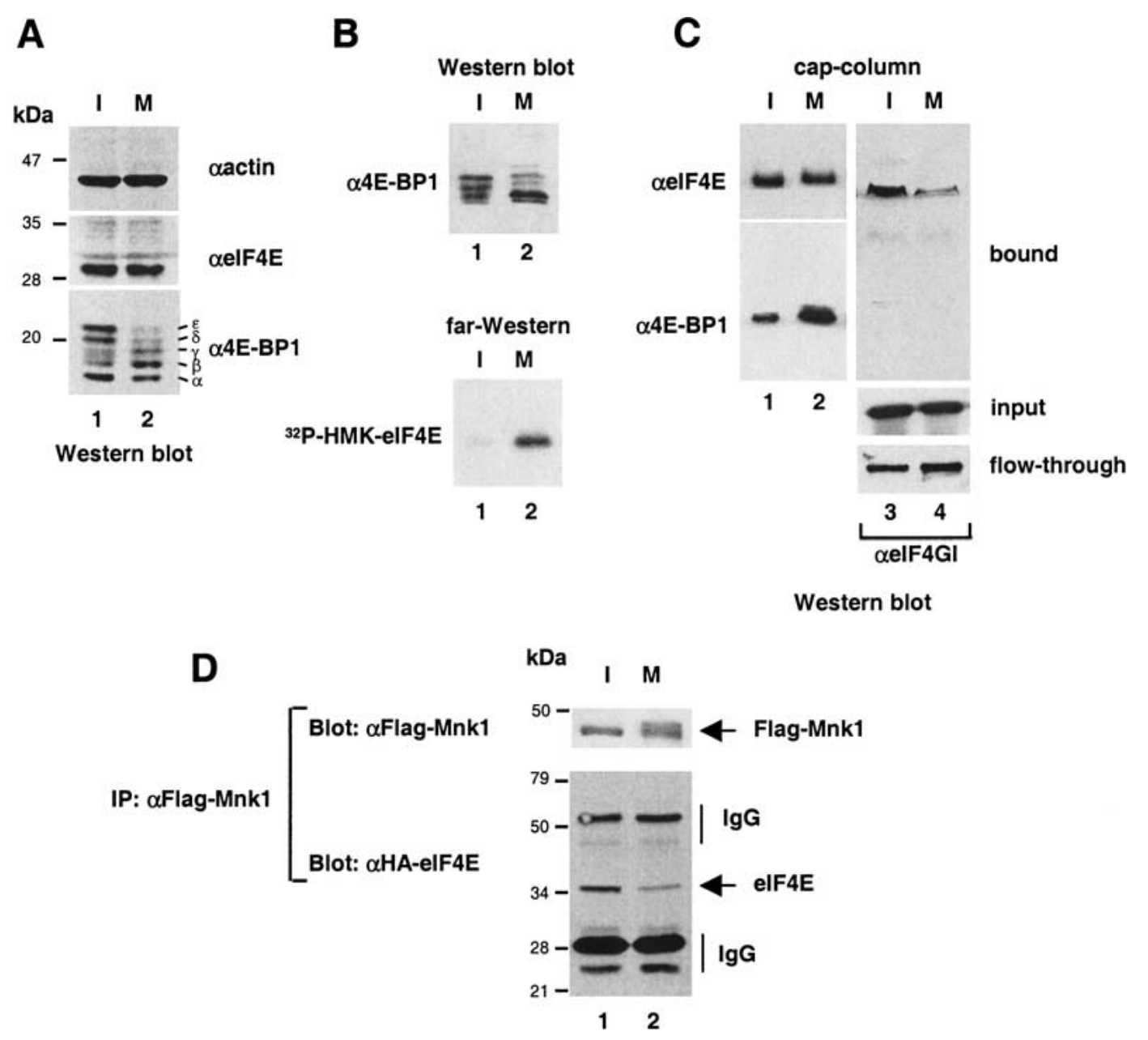

Figure 2. Dephosphorylation and increased binding of 4E-BP1 to eIF4E in mitosis. (A) Hypophosphorylation of 4E-BP1. HeLa cell extract from interphase (I) or nocodazole-arrested (M) cells was resolved by SDS-PAGE, and analyzed by Western blotting with anti-actin (top), anti-eIF4E (middle), or anti 4E-BP1 (bottom). (B) Increased binding of 4E-BP1 to eIF4E. HeLa cell extract from interphase (I) and nocodazole-treated (M) cells was resolved by SDS-PAGE and analyzed by Western blotting with anti-4E-BP1 (top) or by far-Western with ${ }^{32} \mathrm{P}-\mathrm{HMK}$-eIF4E as a probe (bottom). (C) eIF4F complex disruption. Extract from interphase (I) or nocodazolearrested (M) HeLa cells was incubated with an $\mathrm{m}^{7} \mathrm{GDP}$ resin. Input, flow-through, and bound material was resolved by SDS-PAGE and analyzed by Western blotting with the indicated antibodies. (D) Decreased eIF4E/Mnk1 interaction. Extracts from interphase (I) or nocodazole-arrested (M) HeLa cells transfected with Flag-Mnk1 and HA-eIF4E was immunoprecipitated with anti-Flag antibody. Immunoprecipitates were resolved by SDS-PAGE, and analyzed by Western blotting with anti-HA or anti-Flag antibody.

ciprocal experiment using HA-Mnk1 and Flag-eIF4E (data not shown). Thus, dephosphorylation of eIF4E during mitosis can be explained by a reduced association between eIF4E and Mnk1 as a consequence of eIF4F complex disruption.

\section{Hyperphosphorylation of eIF4GII during mitosis}

eIF4GI was reported not to be modified in mitotic cells (Bonneau and Sonenberg 1987). Since this early report was published, a second eIF4G species, eIF4GII, was discovered (Gradi et al. 1998). Therefore, it was of interest to determine whether eIF4GII is modified during mitosis and whether its interaction with eIF4E is changed. An extract from interphase or mitotic HeLa cells was used in immunoprecipitation experiments with anti-eIF4GII antibody, and immunoprecipitates were analyzed by Western blotting using anti-eIF4GII antibody, and by farWestern using ${ }^{32} \mathrm{P}$-HMK-eIF4E as a probe. eIF4GII displayed reduced electrophoretic mobility during mitosis as compared with eIF4GII from interphase cells (Fig. 3A, cf. lanes 1 and 2). Importantly, eIF4E association with the slower migrating form of eIF4GII was decreased as determined by far-Western analysis (Fig. 3A, cf. lanes 3 and 4). To determine whether the reduced gel mobility of eIF4GII was due to phosphorylation, eIF4GII immunoprecipitated from interphase and mitotic cells was phosphatase treated. Treatment increased the mobility of eIF4GII from both interphase and mitotic cells (Fig. 3B, cf. lanes 1 and 2 with 3 and 4), indicating that eIF4GII is a phosphoprotein, and that it is hyperphosphorylated during mitosis. Together, these results suggest that 


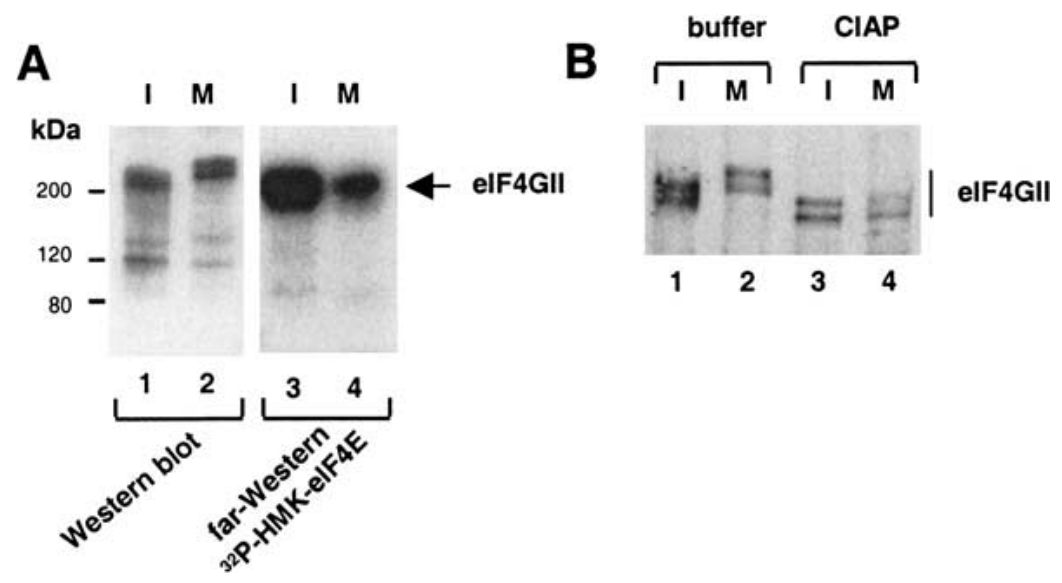

Figure 3. Hyperphosphorylation and decreased binding of eIF4GII to eIF4E in mitosis. (A) Slower electrophoretic mobility of eIF4GII and decreased binding to eIF4E. Total extract from interphase (I) or nocodazole-arrested (M) HeLa cells was resolved by SDS-PAGE and analyzed by Western blotting with anti-eIF4GII antibody, or by far-Western with an ${ }^{32} \mathrm{P}-\mathrm{HMK}-\mathrm{eIF} 4 \mathrm{E}$ probe. (B) Phosphatase treatment of eIF4GII. eIF4GII immunoprecipitated from interphase (I) or nocodazole-arrested (M) HeLa cells was untreated, treated with buffer alone, or with calf intestinal acid phosphatase (CIAP) as described in Materials and Methods. Immunoprecipitates resolved by SDS-PAGE were analyzed by Western blotting with anti-eIF4GII antibody.

phosphorylation of eIF4GII plays a role in the inhibition of eIF4F complex formation during mitosis.

\section{eIF4F integrity throughout the cell cycle}

The experiments described above were performed by use of interphase or mitotic cells. We wished to substantiate these results by monitoring the eIF4E/4E-BP1 interaction progressively throughout the cell cycle. To this end, HeLa cells were arrested at the $G_{1} / S$ boundary by a double thymidine block, released, and collected at different times. A flow cytometry analysis was performed to visualize DNA content, and total extract was analyzed by Western blotting with different antibodies. Following release from the second thymidine block, cells traversed the $S$ phase, then reached the $G_{2} / M$ peak after $8-10 \mathrm{~h}$, and entered $G_{1}$ thereafter (Fig. 4A). Western blotting analysis shows that the amount of eIF4E and 4E-BP1 does not significantly change during the cell cycle, as compared with actin, which was used as a loading control (Fig. 4B). However, 4E-BP1, which is phosphorylated in S-phase (Fig. 4B, lanes 2-5), becomes hypophosphorylated during $G_{2} / M$, as judged by the increase in the $\beta$ and $\gamma$ forms (Fig. 4B, lanes 6 and 7). Subsequently, 4E-BP1 becomes hyperphosphorylated upon $G_{1}$ entry, as assessed by the increase in the $\varepsilon$ and $\delta$ forms (Fig. 4B, lanes 9-11). To examine the eIF4E/4E-BP1 interaction, cell extract was incubated with a cap resin, and bound proteins were analyzed by Western blotting with the indicated antibodies. Hypophosphorylated 4E-BP1 interacts more strongly with eIF4E during $\mathrm{G}_{2} / \mathrm{M}$ (Fig. 4C, lanes 6 and 7), and the hyperphosphorylation observed upon $G_{1}$ entry correlates with decreased eIF4E binding (Fig. 4C, lanes $8-11)$. These results show that eIF4E/4E-BP1 interaction is modulated throughout the cell cycle, as 4E-BP1, which is hypophosphorylated during $G_{2} / M$, becomes hyperphosphorylated upon $G_{1}$ entry.

The magnitude of 4E-BP1 dephosphorylation and consequent eIF4E/4E-BP1 interaction is apparently lower in $\mathrm{G}_{2} / \mathrm{M}$-synchronized cells (Fig. 4) as compared with mitosis-arrested cells (Fig. 2). One explanation for this apparent discrepancy is that the population of cells col- lected 8-10 h following release is not exclusively composed of mitotic cells, but also contains some $G_{2}$ cells. To avoid the contamination with $G_{2}$ cells, a cap-resin assay was performed on extracts from mitotic cells prepared by the mitotic shake-off technique. Bound proteins were analyzed by Western blotting with the indicated antibodies. Whereas similar amounts of eIF4E were retained on the cap-resin, the interaction between eIF4E and the hypophosphorylated forms of 4E-BP1 was strongly enhanced in mitotic cells as compared with interphase cells (Fig. 4D, bottom and middle, cf. lanes 1 and 2). In stark contrast, the amount of eIF4GI retained on the cap-resin was dramatically reduced (Fig. 4D, top, cf. lanes 1 and 2). Importantly, the inhibition of eIF4F formation during mitosis correlated with a strong reduction in the rate of protein synthesis, as assessed by $\left[{ }^{35} \mathrm{~S}\right]$ methionine incorporation into proteins (Fig. 4E). These data show that eIF4F formation is compromised as the cell traverses through mitosis and provide an explanation for the reduction of protein synthesis that occurs at the onset of mitosis.

\section{Hyperphosphorylation of 4E-T during mitosis}

4E-T, the eIF4E-binding protein, which mediates the nuclear import of eIF4E, interacts with eIF4E through a conserved eIF4E-binding motif (Dostie et al. 2000a), and thus, may potentially compete with eIF4Gs to interdict eIF4F complex formation. Therefore, we investigated the possibility that 4E-T may contribute to the inhibition of eIF4F complex formation during mitosis. Interphase or mitotic HeLa cell extracts were analyzed by Western blotting with an anti-4E-T antibody, or by far-Western with ${ }^{32} \mathrm{P}-\mathrm{HMK}-\mathrm{eIF} 4 \mathrm{E}$ as a probe. As for eIF4GII (Fig. $3 \mathrm{~A}, \mathrm{C}), 4 \mathrm{E}-\mathrm{T}$ displays reduced electrophoretic mobility during mitosis (Fig. 5A, cf. lanes 1 and 2), and the slower migrating form of $4 \mathrm{E}-\mathrm{T}$ interacts only weakly with eIF4E as determined by far-Western analysis (Fig. 5A, cf. lanes 3 and 4). Similar results were obtained using a cap column (data not shown).

To determine whether the reduced gel mobility of $4 \mathrm{E}-\mathrm{T}$ is due to phosphorylation, 4E-T immunoprecipi- 


\section{A flow cytometry}
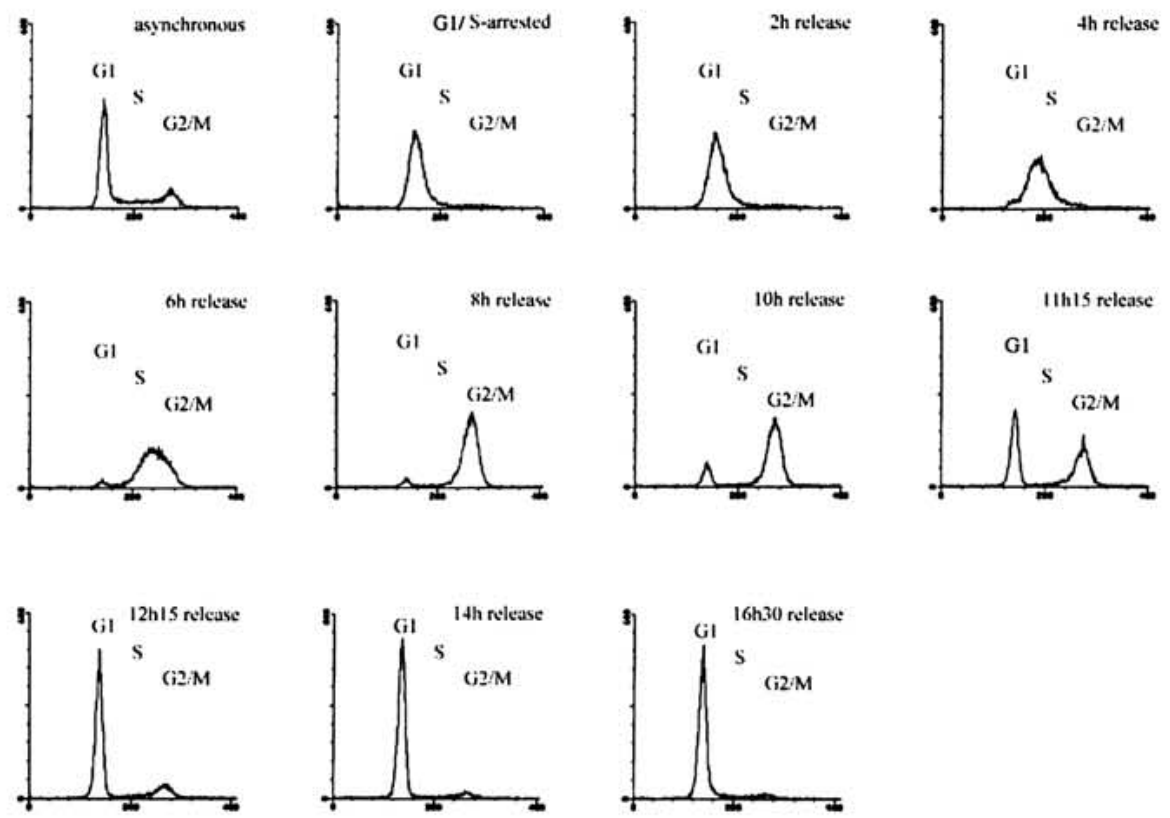

\section{B total extract}

\section{C cap column}
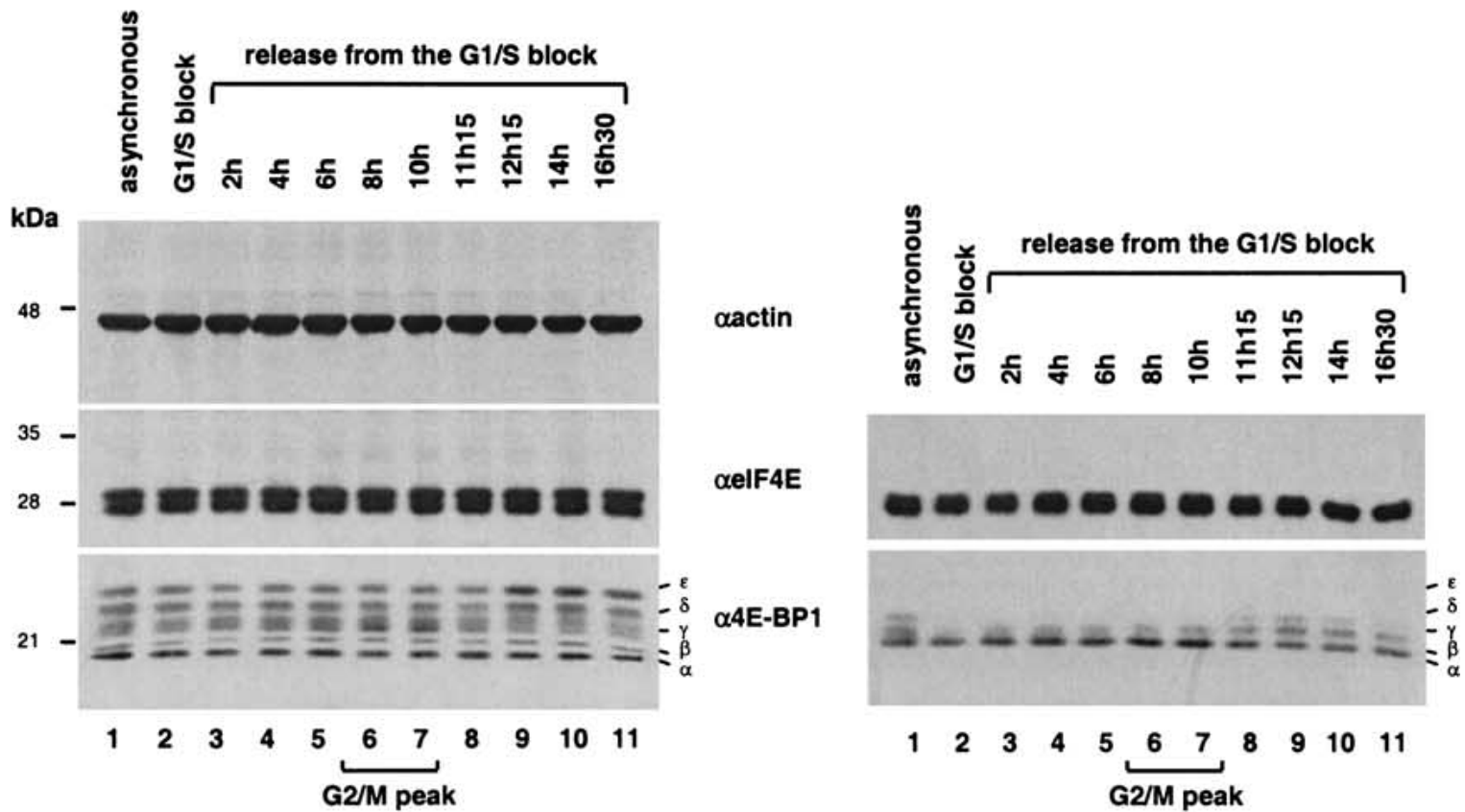

D cap-column

E $\left[{ }^{35} \mathrm{~S}\right]-$ Met incorporation
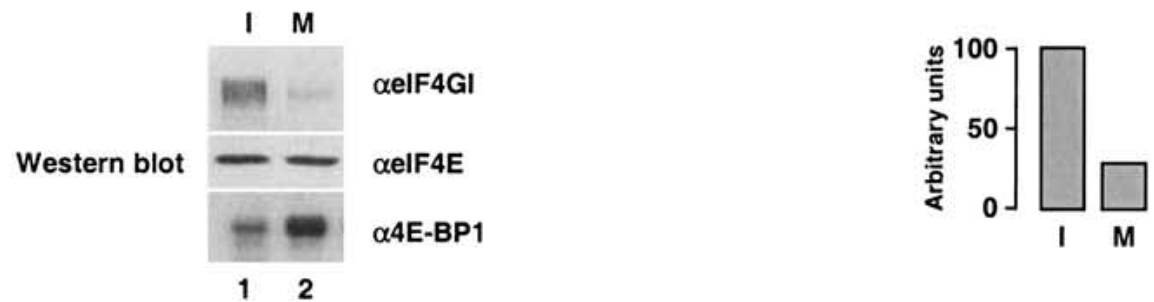

Figure 4. (Legend on facing page) 


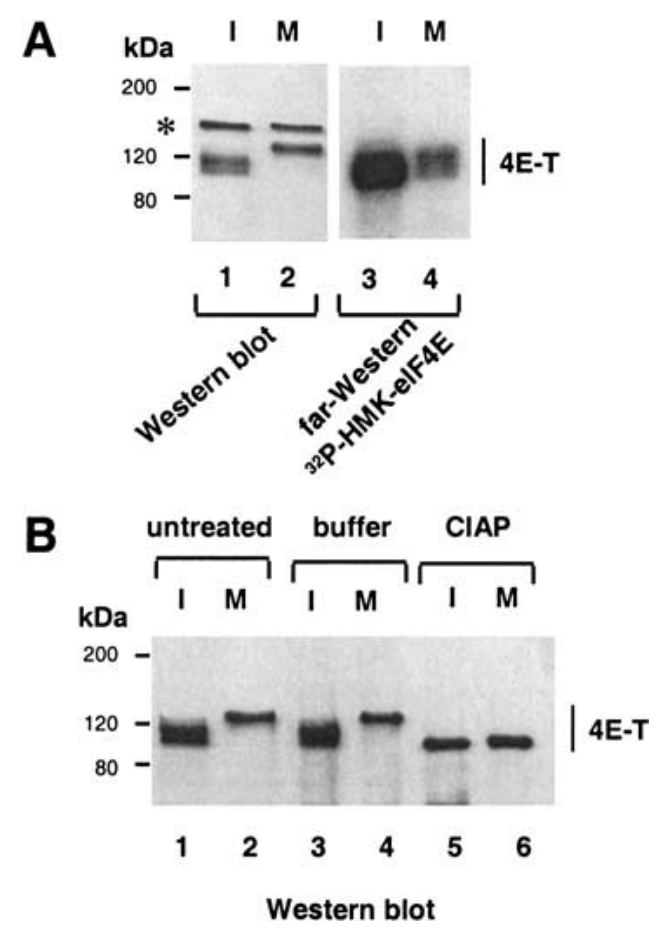

Figure 5. Hyperphosphorylation and decreased binding of 4E-T to eIF4E in mitosis. (A) Slower electrophoretic mobility of 4E-T and decreased binding to eIF4E. Total extract from interphase (I) or nocodazole-arrested (M) HeLa cells was resolved by SDSPAGE, and analyzed by Western blotting with anti-4E-T antibody (lanes 1,2) or by far-Western with an ${ }^{32} \mathrm{P}$-HMK-eIF4E probe $($ lanes 3,4$) .(\star)$ Cross-reacting polypeptide detected in Western blotting, but not following immunoprecipitation. (B) Phosphatase treatment of 4E-T. 4E-T immunoprecipitated from interphase (I) or nocodazole-arrested (M) HeLa cells were untreated, treated with buffer alone, or with CIAP as described in Materials and Methods. Immunoprecipitates were resolved by SDS-PAGE, and analyzed by Western blotting with anti-4E-T antibody.

tated from interphase or mitotic cells was phosphatase treated. This treatment increased the electrophoretic mobility of 4E-T from both interphase and mitotic cells (Fig. 5B, cf. lanes 1-4 with lanes 5 and 6), indicating that 4E-T is a phosphoprotein, and that it is hyperphosphorylated during mitosis. Thus, hyperphosphorylation of 4E-T during mitosis prevents its association with eIF4E. This excludes the possibility that $4 \mathrm{E}-\mathrm{T}$ plays a role in inhibition of eIF4F complex formation in mitotic cells.

\section{Discussion}

The inhibition of cap-dependent translation initiation during $\mathrm{G}_{2} / \mathrm{M}$ creates the need for an alternate cap-independent mechanism of translation for mRNAs encoding unstable proteins, which are required at mitosis. One such mechanism is the direct binding of ribosomes to IRES elements. The mRNAs encoding ornithine decarboxylase (ODC; Pyronnet et al. 2000) and p58 $8^{\text {PITSLRE }}$ (a cdk-like protein; Cornelis et al. 2000) proteins, which have important mitotic functions, translate by an IRESmediated process at mitosis. In addition, two different viral IRESes also function in mitosis, those of poliovirus (Bonneau and Sonenberg 1987) and hepatitis C virus (HCV; Honda et al. 2000). It is then likely that IRESmediated translation initiation is a general mechanism utilized by the cell to bypass the suppression of capdependent translation initiation during mitosis.

Why is there a need for inhibition of cap-dependent translation at mitosis? An intriguing hypothesis is that cap-dependent translation is blocked to avoid translation of capped, yet unspliced, mRNAs that are restricted to the nucleus in the interphase cell, but disperse throughout the cytoplasm as the nuclear envelope breaks down at mitosis (Pinol-Roma and Dreyfuss 1991). Translation of unspliced mRNAs would potentially lead to the accumulation of aberrant proteins, which could act in a dominant-negative manner to inhibit protein function. It could be argued that IRES-containing mRNAs should also be affected. However, in the ODC and p58 ${ }^{\text {PITSLRE }}$ mRNAs, the IRESes span three exons (exons 1-3 for ODC, and exons $8-10$ for p58 ${ }^{\text {PITSLRE }}$ and, therefore, unspliced pre-mRNAs would not possess functional IRESes. This ensures that ODC and p58 $8^{\text {PITSLRE }}$ IRESes would function only in the mature mRNAs, but not in the unspliced pre-mRNAs. Thus, one might anticipate that other IRESes will be discovered in mRNAs encoding proteins that need to be expressed at mitosis, and that these IRESes will span several exons in the spliced mRNA.

The results presented in this study explain how capdependent translation initiation is blocked at mitosis. However, the mechanism responsible for the switch from cap- to IRES-mediated initiation at $\mathrm{G}_{2} / \mathrm{M}$ remains to be addressed. One possibility is that cap-dependent translation and IRES-mediated translation compete with each other, and the inhibition of cap-dependent translation frees initiation factors for IRES-containing mRNAs. Another interesting possibility is that IRES-containing

Figure 4. eIF4E/4E-BP1 expression and interaction throughout the cell cycle. (A) Flow cytometry analysis of HeLa cells following release from a double thymidine block. (x axis) Fluorescence intensity; (y axis) cell number. (B) Expression of eIF4E and 4E-BP1 through the cell cycle. HeLa extract from interphase cells (lane 1), cells arrested at $\mathrm{G}_{1} / \mathrm{S}$ by double-thymidine block (lane 2), and from cells released from a double thymidine block (lanes 3-11) was resolved by SDS-PAGE and analyzed by Western blotting with the indicated antibodies. (C) eIF4E/4E-BP1 interaction through the cell cycle. The extract described in $B$ was incubated with $\mathrm{m}^{7} \mathrm{GDP}$ resin. Bound proteins were resolved by SDS-PAGE and analyzed by Western blotting with the indicated antibodies. $(D)$ eIF4F complex disruption in mitosis. HeLa extract from interphase cells (lane 1) or from cells collected by mitotic shake-off (lane 2) was incubated with $\mathrm{m}^{7} \mathrm{GDP}$ resin. Bound proteins were resolved by SDS-PAGE, and analyzed by Western blotting with the indicated antibodies. (E) Protein synthesis in mitotic versus interphase cells. [35 S]methionine incorporated into TCA precipitable material was measured and expressed in arbitrary units. Values represent the average of two separate experiments. 
mRNAs are specifically targeted to the ribosome by as yet uncharacterized proteins during mitosis. As shown here, the eIF4G-associated Mnk1 kinase is active during mitosis, whereas its eIF4E substrate is underphosphorylated, owing to inhibition of eIF4F assembly. Thus, a mitotic substrate(s) for Mnk1 remain(s) to be identified, and it would be of interest to determine whether such substrate(s) play(s) a role in IRES-mediated translation. Proteins that bind cellular IRESes, such as hnRNPC (Sella et al. 1999) are good candidates. hnRNPC is a nuclear protein, but is released into the cytoplasm during mitosis upon nuclear envelope breakdown (PinolRoma and Dreyfuss 1991). hnRNPC is also specifically phosphorylated in mitosis by an as yet unidentified kinase (Pinol-Roma and Dreyfuss 1993).

Although eIF4GI was reported not to be modified (Bonneau and Sonenberg 1987), we show that eIF4GII is hyperphosphorylated in mitotic cells, suggesting that specific signals target eIF4GII in mitosis. Differential regulation of eIF4GI and eIF4GII is supported by the observation that the phosphorylation sites mapped in the carboxy-terminal two-thirds of the eIF4GI sequence are not phosphorylated in eIF4GII (Raught et al. 2000). Treatment with various kinase inhibitors does not appear to affect the binding of eIF4GI partners including eIF4E, eIF4A, and Mnk1 (Raught et al. 2000). It would therefore be of interest to identify the eIF4GII mitosisspecific phosphorylation sites, and to determine whether phosphorylation impairs eIF4GII interaction with its other binding partners. That these sites could be phosphorylated by Mnk1 during mitosis, is an interesting possibility. eIF4GII is less abundant than eIF4GI in the cell (about three times less; Svitkin et al. 1999). Therefore, it is possible that eIF4GII hyperphosphorylation does not serve primarily to block cap-dependent translation. Instead, hyperphosphorylation might serve to facilitate eIF4GII interaction with other proteins, which could compete with eIF4E for a common binding site on eIF4GII, and enhance its activity in IRES-mediated translation. If so, it would also be important to search for these proteins and to examine their function in IRESmediated translation.

The mechanism and effectors of 4E-BP1 dephosphorylation in mitosis remain to be elucidated. One obvious candidate is the protein phosphatase $2 \mathrm{~A}$ (PP2A). PP2A is required for the progress through mitosis (Mayer-Jaekel et al. 1993), and is able to dephosphorylate 4E-BP1 both in vitro and in vivo (Peterson et al. 1999). Primate lentiviruses arrest cells at the $\mathrm{G}_{2} / \mathrm{M}$ transition /Goh et al. 1998) and lentivirus mRNAs contain IRESes (Ohlmann et al. 2000; Buck et al. 2001). Thus, viral protein synthesis could be enhanced in $\mathrm{G}_{2} / \mathrm{M}$-arrested cells by PP2Adependent dephosphorylation of 4E-BP1, and consequent inhibition of cap-dependent, but stimulation of IRESmediated translation.

4E-T hyperphosphorylation and consequent reduced binding to eIF4E is consistent with the lack of nucleocytoplasmic transport during mitosis. However, the biological significance of this modification is not clear. Although the nuclear function of eIF4E is unknown, eIF4E colocalizes with splicing factors in speckles (Dostie et al. 2000b), suggesting that it could be involved in mRNA processing or even nuclear translation during interphase. 4E-T continuously shuttles between the nucleus and the cytoplasm, but it mainly localizes to the cytoplasm and does not colocalize with eIF4E in the nuclear speckles (Dostie et al 2000a). However, similar to splicing factors (Pinol-Roma and Dreyfuss 1991), eIF4E and nuclear speckles disassemble and reform as cells progress through mitosis (J. Dostie, unpubl.; Spector et al. 1991). Furthermore, overexpression of wild-type 4E-T, but not that of a mutant defective in eIF4E binding, strongly inhibits translation from a reporter construct (J. Dostie, unpubl.). Thus, the loss of interaction between $4 \mathrm{E}-\mathrm{T}$ and eIF4E during mitosis might serve as a mechanism to prevent mislocalization of 4E-T following nuclear envelope assembly, and/or to allow a rapid and efficient resumption of protein synthesis upon $\mathrm{G}_{1}$ entry.

In summary, phosphorylation modifications occur on different partners of eIF4E, including 4E-BP1, eIF4GII, and $4 \mathrm{E}-\mathrm{T}$, in a cell cycle-dependent manner. The hypophosphorylation of 4E-BP1 blocks eIF4E activity, and provides a mechanism to explain the inhibition of capdependent translation in mitosis.

\section{Materials and methods}

\section{Antibodies}

Antibodies against eIF4GI carboxy-terminal (Imataka and Sonenberg 1997), eIF4GII (Gradi et al. 1998), 4E-T (Dostie et al. 2000a), eIF4E (Frederickson et al. 1991), 4E-BP1 (Gingras et al. 1996), and Mnk1 (Fukunaga and Hunter 1997) were described previously. Anti-phospho-eIF4E was generated in collaboration with New England Biolabs. Monoclonal antibodies against actin, Flag, and HA were purchased from Transduction Laboratories, Kodak, and BAbCO, respectively. Peroxidase-coupled antimouse and anti-rabbit IgG were purchased from Amersham.

Cell culture, cell extracts, immunoprecipitation, and Western blotting

HeLa cells were plated in Dulbecco's modified Eagle's medium (DMEM) supplemented with $10 \%$ FBS (complete DMEM). At $\sim 70 \%$ confluency, the cells were washed twice in PBS, scraped, and pelleted by slow centrifugation. Cell pellets were resuspended in either buffer A $(50 \mathrm{mM}$ Tris- $\mathrm{HCl}$ at $\mathrm{pH} 7.4,50 \mathrm{mM}$ $\mathrm{KCl}, 1 \mathrm{mM}$ EDTA, 0.5\% NP-40, and protease inhibitors; Complete, Boehringer Mannheim), or in buffer B (50 mM Tris- $\mathrm{HCl}$ at pH 7.4, $100 \mathrm{mM} \mathrm{NaCl}, 1 \%$ Triton X-100, 1 mM EDTA, $1 \mathrm{mM}$ DTT, protease inhibitors; Complete), and incubated $30 \mathrm{~min}$ at $4^{\circ} \mathrm{C}$. Cell debris was removed by centrifugation at $10,000 \mathrm{~g}$ for 10 $\min$ at $4^{\circ} \mathrm{C}$, and protein concentration was determined using a Bio-Rad assay. Polypeptides were resolved by SDS-PAGE, and transferred onto a nitrocellulose membrane. Membranes were blocked for $16 \mathrm{~h}$ at $4^{\circ} \mathrm{C}$ with $5 \%$ skim milk in PBS containing $0.2 \%$ Tween 20 (PBST). Primary antibodies were incubated for 2 $\mathrm{h}$ at room temperature followed by four 15-min washes in PBST. Membranes were incubated with peroxidase-coupled secondary antibodies for $30 \mathrm{~min}$ at room temperature, and washed four times for $15 \mathrm{~min}$ in PBST. Detection of peroxidase-coupled secondary antibodies was performed with Enhanced-ECL (Amersham Corp.). For drug treatment, cells were incubated in the 
presence of $5 \mu \mathrm{g} / \mathrm{mL}$ aphidicolin (Sigma) or $1 \mu \mathrm{M}$ nocodazole (Sigma) for $24 \mathrm{~h}$ at $37^{\circ} \mathrm{C}$.

\section{Far-Western analysis}

Far-Western experiments were performed as described previously (Pause et al. 1994) using purified mouse Flag-HMK-eIF4E fusion protein $(2.5 \mu \mathrm{g})$, which was ${ }^{32} \mathrm{P}$-labeled with heart muscle kinase (Sigma).

\section{Analysis of eIF4E phosphorylation by isoelectric focusing}

Cell extract was subjected to isoelectric focusing (IEF) with a $\mathrm{pH}$ range of 5-7, in the presence of $9 \mathrm{M}$ urea, $50 \mathrm{mM}$ dithiothreitol, and $2 \%$ CHAPS (Fluka). Proteins were resolved at $5 \mathrm{~mA} / \mathrm{gel}$ for $16 \mathrm{~h}$, with $0.01 \mathrm{M}$ glutamic acid at the catode and $0.02 \mathrm{M} \mathrm{NaOH}$ at the anode. Proteins were transferred onto a nitrocellulose membrane and subjected to Western blotting.

\section{Cell synchronization by double thymidine block and metabolic labeling}

HeLa cells were plated at $30 \%$ confluency in complete DMEM as indicated above. Upon attachment, cells were incubated with $2 \mathrm{mM}$ thymidine (Sigma) in complete DMEM for $15 \mathrm{~h}$, following which the cells were washed three times with DMEM, and incubated in complete DMEM for $9 \mathrm{~h}$. The cells were then incubated a second time with $2 \mathrm{mM}$ thymidine in complete DMEM for $15 \mathrm{~h}$, washed three times with DMEM, and collected at the indicated times. Amino acid incorporation rates were determined as described by Fan and Penman (1970).

\section{Flow cytometry}

Cells $(50,000)$ were trypsinized, collected by centrifugation, and washed twice with cold PBS. Cells were fixed in $50 \%$ methanol/ PBS for at least $1 \mathrm{~h}$ at $4^{\circ} \mathrm{C}$, pelleted by slow centrifugation, and incubated with DNA staining solution $(10 \mathrm{mM}$ Tris- $\mathrm{HCl}$ at $\mathrm{pH}$ 7.0, $5 \mathrm{mM} \mathrm{MgCl} 2,50 \mu \mathrm{g} / \mathrm{mL}$ propidium iodide, and $30 \mu \mathrm{g} / \mathrm{mL}$ RNAse A) for $2 \mathrm{~h}$ at $37^{\circ} \mathrm{C}$. Approximately 10,000 cells from each sample were analyzed, and DNA content was determined using the LYSIS II computer program (Becton Dickinson).

\section{$m^{7} G D P$-agarose binding}

Cells were collected by scraping, washed three times with cold PBS and pelleted by centrifugation. Cell pellets were resuspended in buffer $\mathrm{A}$ and incubated for $30 \mathrm{~min}$ at $4^{\circ} \mathrm{C}$. Cell debris was removed by centrifugation at $10,000 \mathrm{~g}$ for $10 \mathrm{~min}$ at $4^{\circ} \mathrm{C}$, and protein concentration was determined using a Bio-Rad assay. Extract $(650 \mu \mathrm{g})$ was incubated with $25 \mu \mathrm{L}$ of $\mathrm{m}^{7} \mathrm{GDP}$-agarose resin (Edery et al. 1988) for $4 \mathrm{~h}$ at $4^{\circ} \mathrm{C}$. The resin was washed three times with $1 \mathrm{~mL}$ of buffer A, boiled for $6 \mathrm{~min}$ in Laemmli buffer, and proteins were resolved by SDS-PAGE.

\section{Phosphatase treatment}

Following immunoprecipitation, immune complexes were incubated with calf intestine acid phosphatase (CIAP, New England Biolabs) for $30 \mathrm{~min}$ at $30^{\circ} \mathrm{C}$. Reactions were stopped by the addition of Laemmli sample buffer, and proteins were resolved by SDS-PAGE and processed for Western blotting.

\section{In vitro immune complex kinase assay}

Following transfection with Flag-Mnk1 wild type or mutants, unsynchronized or mitotic cells collected by shake-off were lysed in buffer B (supplemented with $50 \mathrm{mM} \beta$-glycero phosphate, $100 \mu \mathrm{M}$ sodium vanadate, and $10 \mathrm{mM} \mathrm{NaF}$ ). Equal amounts of Flag-tagged proteins were immunoprecipitated with anti-Flag agarose-conjugated antibodies (Sigma) for $2 \mathrm{~h}$ at $4^{\circ} \mathrm{C}$. Immune complexes were then washed three times in buffer $\mathrm{B}$ as above, three times in Erk1 kinase assay buffer (Promega), and assayed for kinase activity by incubating with $1 \mu \mathrm{g}$ of recombinant eIF4E and $5 \mu \mathrm{Ci}$ of $\left[\gamma^{32} \mathrm{P}\right] \mathrm{ATP}$ in $30 \mu \mathrm{L}$ of Erk1 kinase assay buffer for $20 \mathrm{~min}$ at $30^{\circ} \mathrm{C}$. Reactions were terminated by the addition of Laemmli sample buffer, and proteins were analyzed by SDS-PAGE and autoradiography.

\section{Acknowledgments}

We thank C. Lister for excellent technical assistance. We also thank R. Fukunaga and T. Hunter for Mnk1 antibody and cDNAs, and R. Polakiewicz, A. Gradi, A.-C. Gingras, and H. Imataka for anti-phospho-eIF4E, anti-eIF4GII, anti-4E-BP1, and anti-eIF4GI antibodies, respectively. This work was supported by grants from the National Cancer Institute of Canada and the Howard Hughes Medical Institute (HHMI) International Scholar Program to N.S. N.S. is a Distinguished Scientist of the Canadian Institute of Health Research and a HHMI International Scholar.

The publication costs of this article were defrayed in part by payment of page charges. This article must therefore be hereby marked "advertisement" in accordance with 18 USC section 1734 solely to indicate this fact.

\section{References}

Bonneau, A.M. and Sonenberg N. 1987. Involvement of the 24$\mathrm{kDa}$ cap-binding protein in the regulation of protein synthesis in mitosis. J. Biol. Chem. 262: 11134-11139.

$\mathrm{Bu}$, X., Haas, D.W., and Hagedorn, C.H. 1993. Novel phosphorylation sites of eukaryotic initiation factor-4F and evidence that phosphorylation stabilizes interactions of the p25 and p220 subunits. J. Biol. Chem. 268: 4975-4978.

Buck, C.B., Shen, X., Egan, M.A., Pierson, T.C., Walker, C.M., and Siliciano, R.F. 2001. The human immunodeficiency virus type 1 gag gene encodes an internal ribosome entry site. J. Virol. 75: 181-191.

Cornelis, S., Bruynooghe, Y., Denecker, G., Van Huffel, S., Tinton, S., and Beyaert, R. 2000. Identification and characterization of a novel cell cycle-regulated internal ribosome entry site. Mol. Cell 5: 597-605.

Dostie, J., Ferraiuolo, M., Pause, A., Adam, S.A., and Sonenberg, N. 2000a. A novel shuttling protein, 4E-T, mediates the nuclear import of the mRNA 5' cap-binding protein, eIF4E. EMBO I. 19: 3142-3156.

Dostie, J., Lejbkowicz, F., and Sonenberg N. 2000b. Nuclear eukaryotic initiation factor 4E (eIF4E) colocalizes with splicing factors in speckles. J. Cell Biol. 148: 239-247.

Duncan, R., Milburn, S.C., and Hershey, J.W.B. 1987. Regulated phosphorylation and low abundance of HeLa cell initiation factor $4 \mathrm{~F}$ suggest a role in translational control. I. Biol. Chem. 262: 380-388.

Edery, I., Altmann, R., and Sonenberg, N . 1988. High-level synthesis in Escherichia coli of functional cap-binding eukaryotic initiation factor eIF-4E and affinity purification using a simplified cap-analog resin. Gene 74: 517-525.

Etchison, D., Milburn, S.C., Edery, I., Sonenberg, N., and Hershey, J.W.B. 1982. Inhibition of HeLa cell protein synthesis following poliovirus infection correlates with the proteolysis 
of a 220,000 dalton polypeptide associated with eukaryotic initiation factor 3 and a cap binding protein complex. J. Biol. Chem. 257: 14806-14810.

Fan, H. and Penman, S. 1970. Regulation of protein synthesis in mammalian cells. J. Mol. Biol. 50: 655-670.

Flynn, A. and Proud, C.G. 1995. Ser209, but not Ser53, is the major site of phosphorylation in initiation factor eIF4E in serum treated chinese hamster ovary cells. J. Biol. Chem. 270: $21684-21688$.

Frederickson, R.M., Montine, K.S., and Sonenberg, N. 1991. Phosphorylation of eukaryotic translation initiation factor 4E is increased in Src-transformed cell lines. Mol. Cell. Biol. 11: 2896-2900.

Fukunaga, R. and Hunter, T. 1997. Mnk1, a new MAP kinaseactivated protein kinase, isolated by a novel expression screening method for identifying protein kinase substrates. EMBO I. 16: 1921-1933.

Gingras, A.-C., Svitkin, Y.V., Belsham, G.J., Pause, A., and Sonenberg, N. 1996. Activation of the translational repressor 4E-BP1 following infection with encephalomyocarditis virus and poliovirus. Proc. Natl. Acad. Sci. 93: 5578-5583.

Gingras, A.C., Raught, B., and Sonenberg, N. 1999. eIF4 initiation factors: Effectors of mRNA recruitment to ribosomes and regulators of translation. Annu. Rev. Biochem. 68: 913963.

Goh, W.C., Rogel, M.E., Kinsey, C.M., Michael, S.F., Fultz, P.N., Nowak, M.A., Hahn, B.H., and Emerman, M. 1998. HIV-1 Vpr increases viral expression by manipulation of the cell cycle: A mechanism for selection of Vpr in vivo. Nat. Med. 4: 65-71.

Gradi, A., Imataka, H., Svitkin, Y.V., Rom, E., Raught, B., Morino, S., and Sonenberg, N. 1998. A novel functional human eukaryotic translation initiation factor 4G. Mol. Cell. Biol. 18: 334-342.

Haghighat, A. and Sonenberg, N. 1997. eIF4G dramatically enhances the binding of eIF4E to the mRNA $5{ }^{\prime}$-cap structure. $J$. Biol. Chem. 272: 21677-21680.

Haghighat, A., Mader, S., Pause, A., and Sonenberg, N. 1995. Repression of cap-dependent translation by 4E-binding protein 1: Competition with p220 for binding to eukaryotic initiation factor-4E. EMBO J. 14: 5701-5709.

Hershey, J.W.B. and Merrick, W.C. 2000. Pathway and mechanism of initiation of protein synthesis. In Translational control of gene expression (ed. N. Sonenberg, J.W.B. Hershey, and M.B. Mathews), pp. 33-126. Cold Spring Harbor Laboratory Press, Cold Spring Harbor, NY.

Honda, M., Kaneko, S., Matsushita, E., Kobayashi, K., Abell, G.A., and Lemon, S.M. 2000. Cell cycle regulation of hepatitis $\mathrm{C}$ virus internal ribosomal entry site-directed translation. Gastroenterology 118: 152-162.

Imataka, H. and Sonenberg, N. 1997. Human eukaryotic translation initiation factor 4G (eIF4G) possesses two separate and independent binding sites for eIF4A. Mol. Cell. Biol. 17: 6940-6947.

Jang, S.K., Krausslich, H.G., Nicklin, M.J., Duke, G.M., Palmenberg, A.C., and Wimmer, E. 1988. A segment of the $5^{\prime}$ nontranslated region of encephalomyocarditis virus RNA directs internal entry of ribosomes during in vitro translation. J. Virol. 62: 2636-2643.

Joshi, B., Cai, A.L., Keiper, B.D., Minich, W.B., Mendez, R., Beach, C.M., Stepinski, J., Stolarski, R., Darzynkiewicz, E., and Rhoads, R.E. 1995. Phosphorylation of eukaryotic protein synthesis initiation factor 4E at Ser209. J. Biol. Chem. 270: 14597-14603.

Lin, T.A., Kong, X., Haystead, T.A.J., Pause, A., Belsham, G.J., Sonenberg, N., and Lawrence, J.C. 1994. PHAS-I as a link between mitogen-activated protein kinase and translation initiation. Science 266: 653-656.

Mader, S., Lee, H., Pause, A., and Sonenberg, N. 1995. The translation initiation factor eIF-4E binds to a common motif shared by the translation factor eIF- $4 \gamma$ and the translational repressors, 4E-binding proteins. Mol. Cell. Biol. 15: 49904997.

Marcotrigiano, J., Gingras, A.C., Sonenberg, N., and Burley, S.K. 1999. Cap-dependent translation initiation in eukaryotes is regulated by a molecular mimic of eIF4G. Mol. Cell 3: 707716.

Mayer-Jaekel, R.E., Ohkura, H., Gomes, R., Sunkel, C.E., Baumgartner, S., Hemmings, B.A., and Glover, D.M. 1993. The $55 \mathrm{kd}$ regulatory subunit of Drosophila protein phosphatase 2A is required for anaphase. Cell 72: 621-633.

Minich, W.B., Balasta, M.L., Goss, D.J., and Rhoads, R.E. 1994. Chromatographic resolution of in vivo phosphorylated and nonphosphorylated eukaryotic translation initiation factor eIF-4E: Increased cap affinity of the phosphorylated form. Proc. Nat1. Acad. Sci. 91: 7668-7672.

Ohlmann, T., Rau, M., Pain, V.M., and Morley, S. 1996. The C-terminal domain of eukaryotic protein synthesis initiation factor (eIF) 4G is sufficient to support cap-independent translation in the absence of eIF4E. EMBO J. 15: 1371-1382.

Ohlmann, T., Lopez-lastra, M., and Darlix, J.-L. 2000. An internal ribosome entry segment promotes translation of the simian immunodeficiency virus genomic RNA. 2000. J. Biol. Chem. 275: 11899-11906.

Pause, A., Belsham, G.J., Gingras, A.-C., Donzé, O., Lin, T.A., Lawrence, J.C., and Sonenberg, N. 1994. Insulin-dependent stimulation of protein synthesis by phosphorylation of a regulator of 5'-cap function. Nature 371: 762-767.

Pelletier, J. and Sonenberg, N. 1985. Insertion mutagenesis to increase secondary structure within the 5 ' noncoding region of a eukaryotic mRNA reduces translational efficiency. Cell 40: $515-526$.

1988. Internal initiation of translation of eukaryotic mRNA directed by a sequence derived from poliovirus RNA. Nature 334: 320-325.

Peterson, R.T., Desai, B.N., Hardwick, J.S., and Schreiber, S.L. 1999. Protein phosphatase 2A interacts with the 70-kDa S6 kinase and is activated by inhibition of FKBP12-rapamycin associated protein. Proc. Natl. Acad. Sci. 96: 4438-4442.

Pinol-Roma, S. and Dreyfuss, G. 1991. Transcription-dependent and transcription-independent nuclear transport of hnRNP proteins. Science 253: 312-314.

. 1993. Cell cycle-regulated phosphorylation of the premRNA-binding (heterogeneous nuclear ribonucleoprotein) C proteins. Mol. Cell. Biol. 13: 5762-5770.

Pyronnet, S. and Sonenberg, N. 2001. Cell cycle-dependent translational control. Curr. Opin. Genet. Dev. 11: 13-18.

Pyronnet, S., Imataka, H., Gingras, A.-C., Fukunaga, R., Hunter, T., and Sonenberg, N. 1999. Human eukaryotic translation initiation factor 4G (eIF4G) recruits Mnk1 to phosphorylate eIF4E. EMBO J. 18: 270-279.

Pyronnet, S., Pradayrol, L., and Sonenberg, N. 2000. A cell cycledependent internal ribosome entry site. Mol. Cell 5: 607616.

Raught, B., Gingras, A.-C., Gygi, S.P., Imataka, H., Morino, S., Gradi, A., Aebersold, R., and Sonenberg, N. 2000. Serumstimulated, rapamycin-sensitive phosphorylation sites in the eukaryotic translation initiation factor 4GI. EMBO $J$. 19: 434-444.

Sachs, A. 2000. Cell cycle-dependent translation initiation: IRES elements prevail. Cell 101: 243-245.

Sella, O., Gerlitz, G., Le, S.-Y., and Elroy-Stein, O. 1999. Differ- 
entiation-induced internal translation of c-sis mRNA: Analysis of the cis elements and their differentiation-linked binding to the hnRNP C protein. Mol. Cell. Biol. 19: 54295440.

Shatkin, A. 1976. Capping of eukaryotic mRNAs. Cell 9: 645653.

Spector, D.L., Fu, X.D., and Maniatis, T. 1991. Associations between distinct pre-mRNA splicing components and the cell nucleus. EMBO J. 10: 3467-3481.

Svitkin, Y., Gradi, A., Imataka, H., Morino, S., and Sonenberg, N. 1999. Eukaryotic initiation factor 4GII (eIF4GII), but not eIF4GI, cleavage correlates with inhibition of host cell protein synthesis after human rhinovirus infection. J. Virol. 73: 3467-3472.

Tamemoto, H., Kadowaki, T., Tobe, K., Ueki, K., Izumi, T., Chatani, Y., Kohno, M., Kasuga, M., Yazaki, Y., and Akanuma, Y. 1992. Biphasic activation of two mitogen-activated protein kinases during the cell cycle in mammalian cells. J. Biol. Chem. 267: 20293-20297.

Tuazon, P.T., Morley, S.J., Dever, T.E., Merrick, W.C., Rhoads, R.E., and Traugh, J.A. 1990. Association of initiation factor eIF-4E in a cap-binding complex (eIF-4F) is critical for and enhances phosphorylation by protein kinase C. J. Biol. Chem. 265: 10617-10621.

Wang, X., Flynn, A., Waskiewicz, A.J., Webb, B.L., Vries, R.G., Baines, I.A., Cooper, J.A., and Proud, C.G. 1998. The phosphorylation of eukaryotic initiation factor eIF4E in response to phorbol esters, cell stresses, and cytokines is mediated by distinct MAP kinase pathways. J. Biol. Chem. 273: 93739377.

Waskiewicz, A.J., Flynn, A., Proud, C.G., and Cooper, J.A. 1997. Mitogen-activated protein kinases activate the serine/threonine kinases Mnk1 and Mnk2. EMBO J. 16: 1909-1920.

Waskiewicz, A.J., Johnson, J.C., Penn, B., Mahalingam, M., Kimball, S.R., and Cooper, J.A. 1999. Phosphorylation of the capbinding protein eukaryotic translation initiation factor 4E by protein kinase Mnk1 in vivo. Mol. Cell. Biol. 19: 1871-1880.

Wright, J.H., Munar, E., Jameson, D.R., Andreassen, P.R., Margolis, R.L., Seger, R., and Krebs, E.G. 1999. Mitogen-activated protein kinase kinase activity is required for the $\mathrm{G}(2) / \mathrm{M}$ transition of the cell cycle in mammalian fibroblasts. Proc. Natl. Acad. Sci. 96: 11335-11340. 


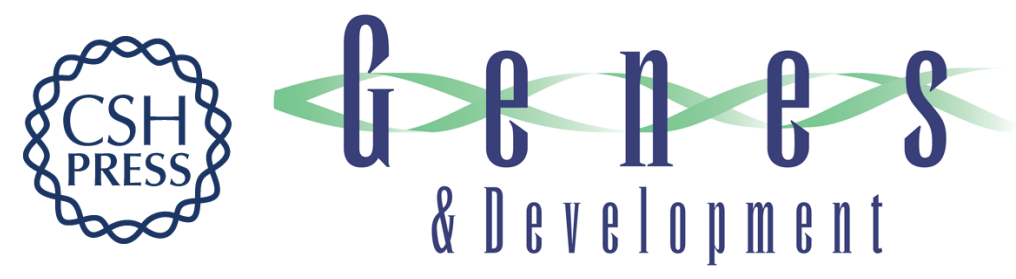

\section{Suppression of cap-dependent translation in mitosis}

Stéphane Pyronnet, Josée Dostie and Nahum Sonenberg

Genes Dev. 2001, 15:

Access the most recent version at doi:10.1101/gad.889201

References This article cites 51 articles, 32 of which can be accessed free at: http://genesdev.cshlp.org/content/15/16/2083.full.html\#ref-list-1

License

Email Alerting Receive free email alerts when new articles cite this article - sign up in the box at the top Service right corner of the article or click here.

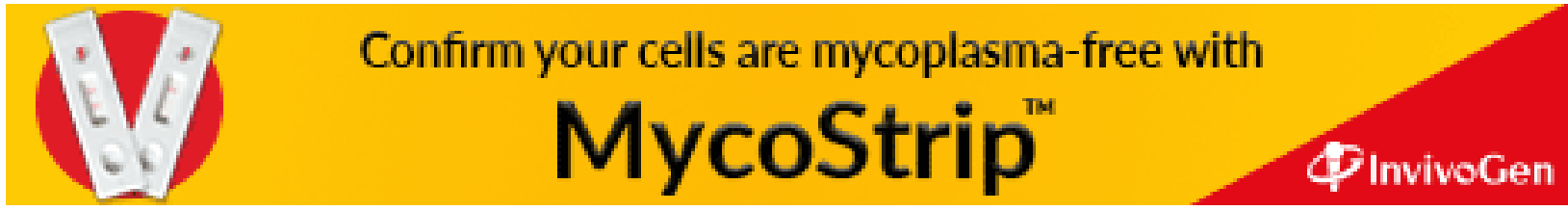

